\title{
The Metabolic Activity of Innate Immunity Cells in Experimental Infection Caused by Various Plasmid Types of Yersinia Pseudotuberculosis
}

\author{
Larisa Mikhailovna Somova, ${ }^{1}$, , Irina Nikolaevna Lyapun ${ }^{1}$, Elena Igorevna Drobot ${ }^{1}$, \\ Felix Nikolayevich Shubin ${ }^{1}$, Natalya Gennadyevna Plekhova ${ }^{2}$ \\ ${ }^{1}$ Ministry of Science and Higher Education, Somov Institute of Epidemiology and Microbiology, Vladivostok, Russian Federation \\ ${ }^{2}$ Ministry of Health of Russia, Pacific Medical University, Vladivostok, Russian Federation
}

Email address:

1_somova@mail.ru (L. M. Somova)

${ }^{*}$ Corresponding author

\section{To cite this article:}

Larisa Mikhailovna Somova, Irina Nikolaevna Lyapun, Elena Igorevna Drobot, Felix Nikolayevich Shubin, Natalya Gennadyevna Plekhova. The Metabolic Activity of Innate Immunity Cells in Experimental Infection Caused by Various Plasmid Types of Yersinia Pseudotuberculosis. Biochemistry and Molecular Biology. Vol. 3, No. 3, 2018, pp. 49-55. doi: 10.11648/j.bmb.20180303.11

Received: September 18, 2018; Accepted: October 5, 2018; Published: November 1, 2018

\begin{abstract}
In a comparative aspect, the functional state of inflammation effector cells in animals infected with various plasmid types of Yersinia pseudotuberculosis was studied. The metabolic activity of peritoneal exudate cells has been investigated in an experimental infection caused by four plasmid types of Y. pseudotuberculosis: type $82^{+}: 48^{+}$, containing two plasmids pVM 82 and pYV; type $82^{+}: 48^{-}$containing single pVM 82 plasmid; type $48^{+}: 82^{-}$containing single pYV plasmid; plasmid-free type 48: 82\%. The parameters of enzyme activity (ATP-ase, 5'-nucleotidase, lactate dehydrogenase, myeloperoxidase) and the level of nitric oxide metabolites were determined. The variability of the metabolic activity of the cells in the inflammatory focus (peritoneal exudate containing neutrophils and macrophages) in infected animals has been established. In response to infection with Y. pseudotuberculosis strain containing two plasmids pYV and pVM82, the production of the nitric oxide metabolites, rather than the active forms of oxygen, had the primary importance in providing the bactericidal potential of phagocytes, compared to animals infected with a strain containing a single pVM82 plasmid. It was concluded that a special biological effect associated with the pVM 82 plasmid available in the Far Eastern strains of the causative agent of epidemic pseudotuberculosis (Far Eastern scarlet-like fever) was involved in the provision of predominantly nitroxide-dependent bactericidal mechanisms of innate immunity cells in this infection.
\end{abstract}

Keywords: Metabolic Activity, Innate Immunity Cells, ATPase, Lactate Dehydrogenase, Myelo Peroxidase, Nitric Oxide Metabolites, Stimulation Index (T), Variability, Plasmid Types of Yersinia Pseudotu Berculosis

\section{Introduction}

Currently, the causative agent of pseudotuberculosis infection, Yersinia pseudotuberculosis as the progenitor of $Y$. pestis, the pathogen of especially dangerous plague infection [1], attracts much attention of researchers as a model for studying the pathogenicity factors of Yersinia and the discovery of molecular mechanisms of interaction in the host-microorganism system [2]. The survival strategy of the Yersinia genus bacteria in the host organism is based on their ability to overcome the mechanisms of innate immunity [3].
Y. pseudotuberculosis has a large set of pathogenicity factors, some of which are encoded by chromosomal genes, and some are encoded by plasmid genes [4-6]. The virulence of the Yersinia genus bacteria is associated with the presence of the pYV plasmid with a molecular mass of 42-48 Mda. This plasmid codes up to 20 species of toxic Yersinia outer membrane proteins (Yop-s), their ability to type III bacterial secretion (T3SS) [7] and the stability of these bacteria to phagocytosis [8-10]. The particular interest is the little studied Y. pseudotuberculosis extrachromosomal replicon, a plasmid with a molecular weight of $82 \mathrm{MDa}$ (pVM 82 plasmid), which is found only in Y. pseudotuberculosis 
strains serovar I - the most common etiologic agent of epidemic pseudotuberculosis (Far Eastern scarlet-like fever, FESLF) in humans. The ability of Y. pseudotuberculosis to cause epidemic outbreaks of infection in the population is due to the simultaneous presence of two plasmids $\mathrm{pYV}$ and pVM 82 in the microbe, which determine the specific virulence of the strains [4]. It is assumed that the Y. pseudotuberculosis strains carrying pVM 82 plasmid have apoptosis-inducing and immunosuppressive effects $[11,12]$.

It is established [13] that plasmid-containing $Y$. pseudotuberculosis strains are more resistant to destruction by macrophages and neutrophils than bacteria of a plasmidfree strain. Bacteria that carry a combination of plasmids (pYV48: pVM 82) suppress the oxidative explosion in macrophages and neutrophils, reduce the activity of superoxide dismutase, myeloperoxidase and acid phosphatase, reduce the non-enzymatic cationic proteins and thus inhibit the bactericidal ability of phagocytes $[14,15]$. The morphofunctional state and patterns of bactericidal reactions of phagocytes in their interaction with various plasmid types of Y. pseudotuberculosis have been studied fragmentarily, and the reaction of innate immunity cells determined by pVM 82 plasmid of Y. pseudotuberculosis remains the least studied. On this question for the last three years a published works were not detected. In this connection, the purpose of this work was to study in a comparative aspect of the metabolic state of innate immunity cells in animals infected with various plasmid types of Y. pseudotuberculosis.

\section{Material and Methods}

\subsection{Laboratory Animals}

To reproduce the experimental infection, white male mice weighing $18-20 \mathrm{~g}$ (200 individuals) were infected intraperitoneally. Animals were on a standard diet in boxed rooms in compliance with all rules and international recommendations of the European Convention.

\subsection{Bacteria}

For the infection, strains of the four plasmid types of $\mathrm{Y}$. pseudotuberculosis were obtained from the collection of Somov Research Institute of Epidemiology and Microbiology: 1) $\mathrm{H}-5015 \mathrm{~T}^{+}$strain $\left(82^{+}: 48^{+}\right)$containing two plasmids $\mathrm{pVM}$ 82 and pYV, $\mathrm{LD}_{50}$ was $3.7 \times 10^{7}$, the infecting dose $4 \times 10^{8}$; 2) $\mathrm{H}-5015 \mathrm{~T}^{-}$strain $\left(82^{+}: 48^{-}\right)$containing single pVM 82 plasmid, the infecting dose $4 \times 10^{8}$; 3) $\mathrm{H}-5013 \mathrm{~T}^{+}$strain $\left(48^{+}\right)$ containing single pYV plasmid, $\mathrm{LD}_{50}$ was $1.4 \times 10^{8}$, the infecting dose $2 \times 10^{9}$; 4) H-5013 $\mathrm{T}^{-}$plasmid-free strain $\left(48^{-}\right)$, the infecting dose $2 \times 10^{9}$. The infecting dose of strains causing a systemic infection was equal to 10 -fold $\mathrm{LD}_{50}$ [16].

The material was taken on 1, 3,5 and 7 days postinfection (pi). To obtain cells of peritoneal exudate, the abdominal cavity of the mice was washed with $5 \mathrm{ml}$ of cold medium 199 containing heparin with a concentration $5 \mathrm{u} / \mathrm{ml}$. The cell suspension was adjusted to a concentration of $2 \times 10^{6}$ cells / $\mathrm{ml}$ and transferred to flat-bottomed 96-well microplates, 100 $\mu 1$ per well. For adhesion, a suspension of peritoneal cells containing neutrophils and macrophages was left in a $\mathrm{CO}_{2}$ incubator at $37^{\circ} \mathrm{C}$, after 40 minutes the cell monolayer was washed twice from unadhered cells, followed by incubation for 3 days in medium 199 containing 5\% fetal bovine serum, $0.004 \%$ gentamicin (KRKA), then washed twice with gentamicin and used for experiments.

\subsection{Evaluation of the Functional State of Cells}

The functional state of the cells was assessed by the activity of enzymes ATPase, 5'-nucleotidase (AMPase), lactate dehydrogenase (LDH), myeloperoxidase (MPO) and by the level of nitric oxide (NO) metabolites.

\subsubsection{ATPase and 5'-Nucleotidase Activity}

$20 \mu \mathrm{l}$ of substrate for ATPase $(8 \mathrm{mg}$ ATP per $1 \mathrm{ml}$ Tris$\mathrm{HCl}$ buffer pH 7.8 containing $87 \mathrm{mg} \mathrm{NaCl}, 28.7 \mathrm{mg} \mathrm{KCl}, 52$ $\mathrm{mg} \mathrm{MgCl}_{2}, 6 \mathrm{H}_{2} \mathrm{O}$ ), and for 5'-nucleotidase (4 mg AMP per $\mathrm{ml}$ of the same buffer containing $87 \mathrm{mg}$ of $\mathrm{NaCl}$ and $70 \mathrm{mg}$ of $\mathrm{MgCl}_{2}$ ) were added to the monolayer of cells, the samples were left for 30 and 60 minutes [17]. The reaction was stopped by the addition of $100 \mu$ of the ascorbic and molybdic acid mixture in a 1: 1 ratio. After 20 minutes, the optical density of the substrates was measured on a Multiscan Titertek Plus spectrophotometer ("Flow lab.", Finland) at 620 nm a wave length.

\subsubsection{Lactate Dehydrogenase Activity}

The method of Z. Loyda in own modification [17] was used. To a fixed monolayer of cells, $100 \mu$ of substrate iodnitrotetrazolium violet (iodnitrotetrazolium, ICN) $2 \mathrm{mg} /$ $\mathrm{ml}$ was added. For this, $20 \mathrm{mg}$ of iodnitrotetrazolium was dissolved first in $0.5 \mathrm{ml}$ of $70^{\circ}$ alcohol, and then $9.5 \mathrm{ml}$ of the above solution was added. The monolayer of the cells together with the substrate was incubated at $37^{\circ} \mathrm{C}$ for 30 minutes, after which the supernatant was removed, the monolayer of cells was washed twice with Hanks's solution and dried. The intracellular granules of Diphenazan were dissolved by adding $100 \mu \mathrm{l}$ of isopropyl alcohol acidified with $0.04 \mathrm{M} \mathrm{HCl}$ for 20 minutes. The optical density of the substrate was determined on a spectrophotometer at $492 \mathrm{~nm}$ a wave length.

\subsubsection{Myeloperoxidase Activity}

The method of Z. Loyda in own modification [17] was used. In the wells of the plates, $100 \mu \mathrm{l}$ of CRF (ophenylenediamine, firm "ICN"), (4 mg per $10 \mathrm{ml}$ ) was added to the fixed cells, based on phosphate-citrate buffer ( $\mathrm{pH} 5.0)$ with the addition of $500 \mu \mathrm{l}$ of $0.33 \%$ hydrogen peroxide. The monolayer of cells was incubated at room temperature for 10 minutes, then the reaction was stopped by adding a $10 \%$ solution of sulfuric acid in $100 \mu \mathrm{l}$ per well. The optical density was determined on a spectrophotometer at $492 \mathrm{~nm}$ a wave length. Blanking was carried out on a solution of CRF and $10 \%$ sulfuric acid.

\subsubsection{Nitric Oxide - Nitrites ( $\left.\mathrm{NO}_{-2}\right)$ Metabolites}

After incubation at $37^{\circ} \mathrm{C}$, the supernatant and cells 
monolayer of the infected animals were frozen and stored at $20^{\circ} \mathrm{C}$. $100 \mu \mathrm{l}$ of Griess reagent was added to the destroyed cells, which consisted of equal volumes of $0.1 \% \mathrm{~N}-(1-$ naphthyl) ethylenediamine dihydrochloride and $1 \% \mathrm{p}$ aminobenzidine-sulfonamide (firm "ICN"), based on $2.5 \%$ solution phosphoric acid [18]. After 10 minutes of contact, the optical density of the obtained substrates was determined on a spectrophotometer at $540 \mathrm{~nm}$ a wave length.

The results of the spectrophotometric analysis of enzyme activity in phagocytes were expressed as a stimulation index (T), in percent, which was calculated by the formula: $\mathrm{T}=$ (No-Nk): Nk x 100, where Nk is the average index of optical density of the test substrate in the cells of the uninfected animals (control); No - the average index of the optical density of the substrate in the cells of infected animals.

\subsection{Statistical Analysis}

Statistical processing of the data was carried out using the software packages "Microsoft Excel 2007", "Statistika 7" with the definition of the arithmetic mean $(\mathrm{M})$, its error $(\mathrm{m} \pm)$, the reliability of the differences (p) and the use of known graphical methods for expressing statistical data.

\section{Result and Discussion}

\subsection{ATPase and 5'-Nucleotidase Activity}

In chemotaxis, the plasma membrane of phagocytes is spatially transformed, and this process is directly dependent on the activity of ectoenzymes - ATPase and 5'nucleotidase, whose activity is high in resting and extremely small in activated cells [19]. We established that in animals infected with Y. pseudotuberculosis, the ATPase activity in the cells of peritoneal exudate had negative values relative to control only in response to $\mathrm{H}-5015 \mathrm{~T}^{+}$strain $\left(82^{+}: 48^{+}\right)$, which indicated stimulation of these cells.

The $\mathrm{T}$ indicators were $-3.79 ;-8.22 ;-7.59$ and $-3.16 \%$, respectively, for $1,3,5$ and 7 days pi. When infected with $\mathrm{H}$ -
$5015 \mathrm{~T}^{-}$strain $\left(82^{+}: 48^{-}\right)$cell stimulation was detected only for 3 days pi $(\mathrm{T}=-5.69 \%)$, and in response to $\mathrm{H}-5013 \mathrm{~T}^{+}$ strain $\left(48^{+}\right)$, ATP-ase activity slightly decreased to $0.63 \%$ for 5 days pi. The indices of 5'-nucleotidase activity had negative values only when infected with $\mathrm{H}-5015 \mathrm{~T}^{+}$strain $\left(82^{+}: 48^{+}\right)$: 2.56 and $-1.48 \%$ respectively on 3 and 7 days pi. When the animals were infected with $\mathrm{H}-5013 \mathrm{~T}^{-}\left(48^{-}\right)$plasmid-free strain, we have established a high activity of ATPase with a fluctuation of 18.98 to $98.10 \%$ and a simultaneous increase in the of 5'-nucleotidase activity from 29.48 to $136.53 \%$ with the maximum values for 7 days pi. Compared with the plasmid-free strain, when infected with $\mathrm{H}-5013 \mathrm{~T}^{+}\left(48^{+}\right)$ strain, containing a single virulence plasmid $\mathrm{pYV}$, the activity level of 5'-nucleotidase was significantly lower (22.43, 19.87 and $3.20 \%$, respectively, by 1,3 and 5 days pi), and positive indices of ATPase activity were approaching the control level. So, in terms of ATPase activity, the distinct stimulation of peritoneal exudate cells occurred only in response to infection with $\mathrm{Y}$. pseudotuberculosis strains containing pVM 82 plasmid, especially in combination with the virulence plasmid pYV. The low level of cell stimulation, probably due to the low virulence of the infecting strains, indicated an insignificant degree of purine catabolism intension.

\subsection{Lactate Dehydrogenase Activity}

At the first stage, to form from the oxygen molecule the superoxide anion of oxygen $\mathrm{O}_{2}$, succinates and lactates may be the electron donor in addition to the NADP-H oxidase complex. Succinate dehydrogenase and lactate dehydrogenase participate in the reaction of their transformation, which are activated at the last stage of glycolysis [20]. The decrease in LDH activity below the control level for pathogenic exposures can be regarded as a decrease in the energy potential of leukocytes, which reflects the presence of an adaptive response of the organism to external, including bacterial, factors.

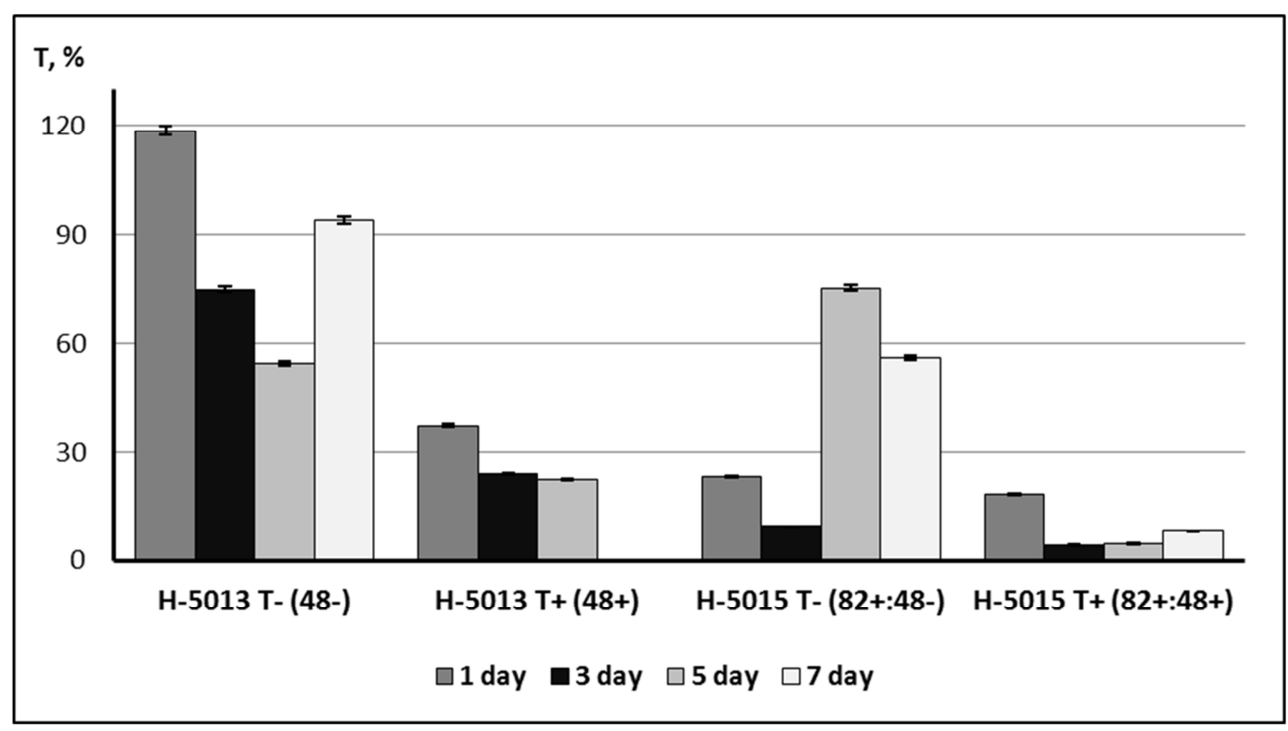

(a) 


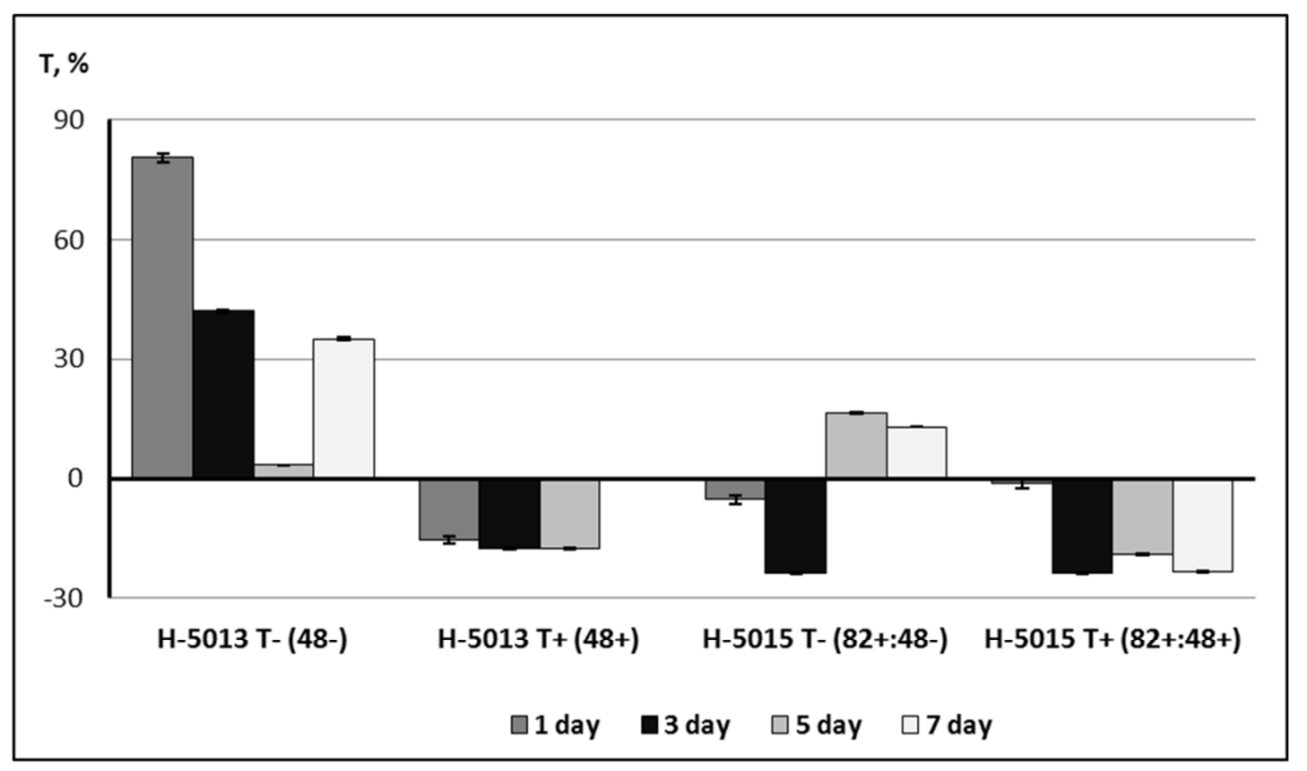

(b)

Figure 1. Activity of enzymes of oxygen-dependent system in cells of peritoneal exudate in animals infected with different Yersinia pseudotuberculosis plasmid types: a) lactate dehydrogenase; b) myeloperoxidase. The stimulation index $T, \%$.

In animals intraperitoneally infected with $Y$. pseudotuberculosis, in the cells of peritoneal exudate, the highest level of LDH activity was revealed in response to the $\mathrm{H}-5013 \mathrm{~T}^{-}\left(48^{-}\right)$plasmid-free strain with a cyclic increase of the stimulation index: $118.5 ; 74.6 ; 54.4$ and $94.1 \%$, respectively, on 1, 3, 5 and 7 days pi (Figure 1a). When infected with $\mathrm{H}-5013 \mathrm{~T}^{+}$strain $\left(48^{+}\right)$containing a single $\mathrm{pYV}$ plasmid the LDH activity was $37.1 ; 24.0$ and $22.3 \%$ on 1,3 and 5 days pi (follow-up period). When infected with H-5015 $\mathrm{T}^{-}\left(82^{+}: 48^{-}\right)$strain, the enzyme activity on 1 day pi increased to $23.2 \%$, then decreased to $9.2 \%$ on 3 day and increased to $75.1 \%$ again on 5 day pi, but until the end of the observation period remained at a high level - up to $56.1 \%$ compared with the control. The level of LDH activity in macrophages was minimal in response to infection with the H-5015 $\mathrm{T}^{+}\left(82^{+}\right.$: $48^{+}$) two-plasmid strain: $18.1 ; 4.2 ; 4.6 \%$, respectively on 1,3 and 5 days pi.

\subsection{Myeloperoxidase Activity}

Myeloperoxidase, present in the azurophilic granules of polymorphonuclear leukocytes, enters the phagolysosome when the cell is activated. This enzyme, by converting the superoxide anion radical into hypochloric acid, protects the cell from an excessive number of reactive oxygen intermediates.

In animals, infected with various plasmid type of $\mathrm{Y}$. pseudotuberculosis, a marked increase in MPO activity in peritoneal exudate cells was detected only in response to the introduction of the $\mathrm{H}-5013 \mathrm{~T}^{-}\left(48^{-}\right)$plasmid-free strain to $80.1 ; 41.9 ; 3.3$ and $34.9 \%$, respectively, on $1,3,5$ and 7 days pi compared with the control (Figure 1b). Such dynamics of the MPO activity level, with the highest index after 1 day pi, can be explained by the influx of neutrophils containing MPO into the inflammatory focus in the early stages of infection. The number of neutrophils in peritoneal exudate on 1 and 3 days pi with a plasmid-free strain was $64 \%$ and $25 \%$, respectively. A slight increase in MPO activity above the control level was noted when infected with $\mathrm{H}-5015 \mathrm{~T}^{-}\left(82^{+}\right.$: $\left.48^{-}\right)$strain containing a single pVM 82 plasmid: $-5.2 ;-23.7$; 16.1 and $12.8 \%$, respectively, on $1,3,5$ and 7 days pi. When the animals were infected with Y. pseudotuberculosis H-5013 $\mathrm{T}^{+}\left(48^{+}\right)$and $\mathrm{H}-5015 \mathrm{~T}^{+}\left(82^{+}: 48^{+}\right)$strains containing the virulence plasmid $\mathrm{pYV}$, the MPO activity had negative values throughout the observation period: in response to the H-5013 $\mathrm{T}^{+}\left(48^{+}\right)$strain $-15, \%$; -17 , on 1, 3-5 days pi and for $\mathrm{H}-5015 \mathrm{~T}^{+}\left(82^{+}: 48^{+}\right)$strain, respectively $-1.3 ;-23.7$ and $19.1 \%$, i.e. below the control level. This indicated a violation of the protective function of phagocytes in response to infection with these plasmid type of Y. pseudotuberculosis. However, it should be noted that when infected with H-5015 $\mathrm{T}^{-}\left(82^{+}: 48^{-}\right)$strain containing a single pVM 82 plasmid, positive values of MPO were found on 5 and 7 days pi: 16.1 and $12.8 \%$, respectively, indicating on the protective reaction of cells from an excessive number of reactive oxygen intermediaries in this period.

\subsection{Production of Nitric Oxide Metabolites}

Recent studies have shown that in the phagocytes stimulated by bacteria and proinflammatory cytokines, along with the production of active metabolites of oxygen, the formation of nitric oxide (NO) occurs, the value of which has been proven in the pathogenesis of various infections [21, 22]. The results of our experiments indicated the accumulation of $\mathrm{NO}$ in the cells of peritoneal exudate and its excretion into the extracellular space in animals infected with various plasmid types of Y. pseudotuberculosis (Figure 2a, b). The level of NO metabolites in peritoneal exudate cells in response to infection with the $\mathrm{H}-5013 \mathrm{~T}^{-}\left(48^{-}\right)$plasmid-free 
strain reached $47.6 ; 57.2 ; 70.5$ and $66.4 \%$ and extracellularly $25.5 ; 55.5 ; 162.5$ and $42.8 \%$, respectively, on $1,3,5$ and 7 days pi. In the infection caused by $\mathrm{H}-5015 \mathrm{~T}^{-}\left(82^{+}: 48^{-}\right)$ strain, containing a single pVM82 plasmid, the NO level was intracellularly to $47.6 ; 19.0 \% 46.0$ and $80.9 \%$, extracellularly $10.3 ; 17.7 \% 8,57,3$ and $37.9 \%$, respectively, on $1,3,5$ and 7 days pi. In the infection caused by $\mathrm{Y}$. pseudotuberculosis strains containing the pYV virulence plasmid, a more pronounced nitroxide-forming activity was established, the level of which was higher when infected with the H-5015 $\mathrm{T}^{+}$ $\left(82^{+}: 48^{+}\right)$two-plasmid strain than the $\mathrm{H}-5013 \mathrm{~T}^{+}\left(48^{+}\right)$strain containing only the $\mathrm{pYV}$ virulence plasmid. In the first case $\left(\left(\mathrm{H}-5015 \mathrm{~T}^{+}\left(82^{+}: 48^{+}\right)\right.\right.$strain $\left.)\right)$, the NO metabolites level was intracellularly to 80,$53 ; 5.1$ and $16.8 \%$, extracellularly 42,$6 ; 4.3$ and $14.9 \%$ on 1,3 and 5 days pi. When infected with $\mathrm{H}-5013 \mathrm{~T}^{+}\left(48^{+}\right)$strain with a single pYV plasmid, the indices were intracellularly to $32.1 ; 57.2$ and $61.7 \%$, extracellularly $38.7 ; 16.7$ and $33.1 \%$ on 1,3 and 5 days pi.

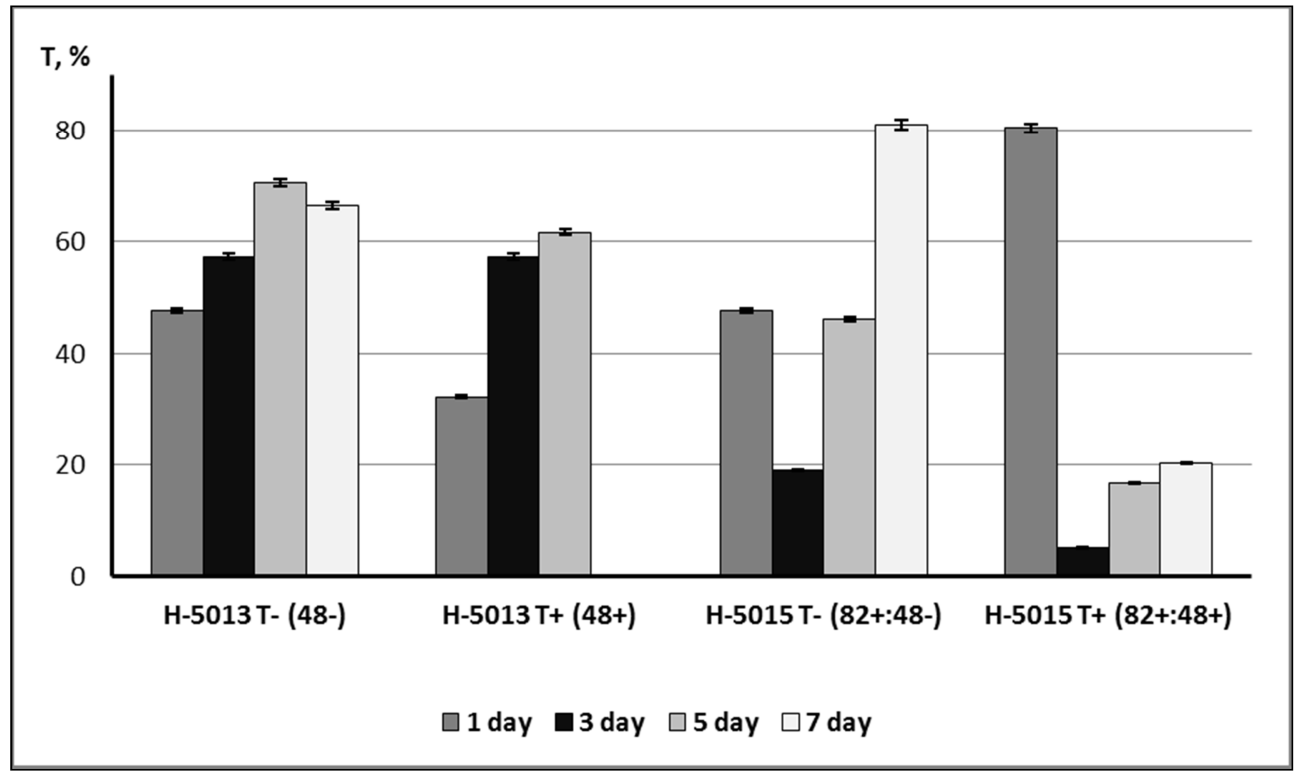

(a)

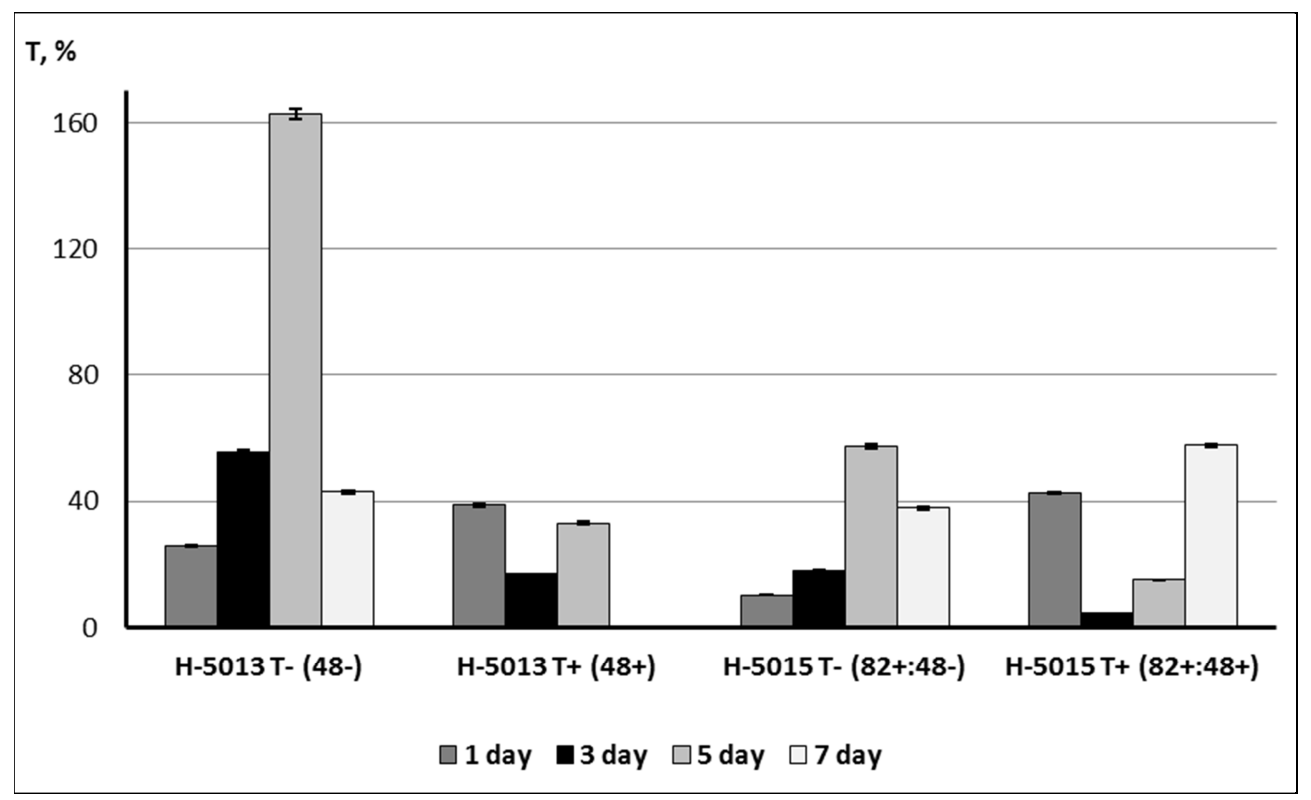

(b)

Figure 2. Nitric oxide metabolites in peritoneal exudate of animals infected with different Yersinia pseudotuberculosis plasmid types: a) intracellular level; b) extracellular level. The stimulation index T,\%.

The obtained results testify about the features of the response of effector inflammatory cells upon infection cause by various plasmid types of $\mathrm{Y}$. pseudotuberculosis. According to the activity index of the plasmalemma ectoenzyme ATPase, the stimulating effect on the cells of peritoneal exudate (neutrophils, macrophages) was provided only by Y. pseudotuberculosis strains containing the pVM 82 plasmid, especially in combination with the pYV virulence 
plasmid. When infected with the Y. pseudotuberculosis plasmid-free strain and strain having a single pYV virulence plasmid, no stimulation of these cells was detected. The Y. pseudotuberculosis plasmid-free strain had an activating effect on the production of lactate dehydrogenase and myeloperoxidase, and also caused a significant increase in the level of nitric oxide metabolites with the release of it into the extracellular space. This indicated the realization of the bactericidal potential of these cells in infected animals. Compared with the plasmid-free strain, when infected with $\mathrm{Y}$. pseudotuberculosis strain containing only the pYV virulence plasmid, the LDH activity was much less pronounced, the MPO activity was negative, and the intracellular accumulation of NO revealed a weak excretion of it into the extracellular space, which allowed to assume the violation of the protective reaction of innate immunity cells.

\section{Conclusion}

Based on the presented results, a conclusion was made on the variability of the metabolic activity of innate immunity cells when infected with different plasmid types of Y. pseudotuberculosis. In response to infection with the plasmid type of Y. pseudotuberculosis containing two plasmids pYV and pVM 82, in providing the bactericidal potential of phagocytes a primary importance had a production of nitric oxide metabolites, compared with the plasmid type containing a single pVM 82 plasmid. This indicates the participation of a special biological effect associated with pVM 82 plasmid, contained in the Far Eastern strains of the causative agent of epidemic pseudotuberculosis (Far Eastern scarlet-like fever), in providing mainly nitroxide-dependent mechanisms of bactericidal activity of innate immunity cells at this infection.

Abbreviations: AMPase: adenosine monophosphatase; ATPase: adenosine triphosphatase; MDa: megadalton; MPO: myeloperoxidase; LDH: lactate dehydrogenase; NO: nitric oxide; pi: postinfection

\section{References}

[1] Skurnik M., Peippo A., Ervelia E. (2000) Characterization of the $\mathrm{O}$-antigen gene clusters of $\mathrm{Y}$. pseudotuberculosis and the criptic O-gene cluster of $\mathrm{Y}$. pestis shows that the plague bacillis is the most closely related to and has evolved from Y. pseudotuberculosis serotype O: 1b. Mol Microbiol 37: 316330 .

[2] Somova L. M., Andryukov B. G., Plekhova N. G. (2015) The problem of yersiniosis in the modern world. Intern J. Appl Basic Res 12: 661-667.

[3] Philip N. H., Brodsky I. E. (2012) Cell death programs in Yersinia immunity and pathogenesis. Front Cell Infect Microbiol 2 (149): 1-7.

[4] Somov G. P., Pokrovsky V. I., Besednova N. N., Antonenko F. F. (2001) Pseudotuberculosis. M.: Medicine.

[5] Shurygina I. A., Chesnokova M. V., Klimov V. T., Malov I.
V., Maramovich A. S. (2003) Pseudotuberculosis. Novosibirsk: Science.

[6] Somova L. M., Shubin F. N., Drobot E. I., Plekhova N. G., Lyapun I. N. (2016) Plasmid-associated virulence of Yersinia pseudotuberculosis and infectious process. J Microbiol Epidemiol Immunobiol 6: 74-84.

[7] Brodsky I. E., Palm N. W., Sadanand S., Ryndak M. B., Sutterwala F. S. et al. (2010) Effector promotes virulence by preventing inflammasome recognition of the type III secretion system. Cell Host Microbe. 7 ( 5): 376-387.

[8] Timchenko N. F., Adgamov R. R., Popov A. F., Psareva E. K., Sobyanin K. A., Gintsburg A. L., Ermplaeva S. A. (2016) East Scarlet-like fever caused by a Few related genotypes of Yersinia pseudotuberculosis. Emerging Infest Dis 22 (3): 503506.

[9] Cornelis G. R. (2010) The type III secretion injectisome, a complex nanomachine for intracellular toxin delivery. Biol Chem 391 (7): 745-751.

[10] Groves E. 1., Rittinger K., Amstutz M., Berry S., Holden D. W., Cornelis G. R., Caron E. (2010) Sequestering of Rac by the Yersinia effector YopO blocks Fc gamma receptormediated phagocytosis. J Biol Chem 285 (6): 4087-4098.

[11] Naberezhnykh G. A., Sidorin E. V., Lapshina L. A., Reunov A. V., Solovyova T. F. (2006) Influence of cultivation conditions and virulence plasmids on the expression of immunoglobulinbinding proteins Yersinia pseudotuberculosis. Biochemistry 71 (11): 1577-1582.

[12] Sever I. S. (1996) Effect of pVM82 Yersinia pseudotuberculosis on the activity of complement components and phagocytosis by human blood neutrophils. Mol Gen Microbiol Virol 1: 23-26.

[13] Shurygina I. A., Malov A. V., Maramovich A. S., Klimov V. T. (2001) The effect of a plasmid with 82 MD molecular weight on the clinical and morphological manifestations of pseudotuberculosis. Sib Med J 26 (1): 48-53.

[14] Dubrovina V. I., Golubinsky E. P., Borsuk G. I., Balakhonov S. V., Konovalova Zh. A. (1999) Features of Yersinia pseudotuberculosis phagocytosis with a different set of plasmids. Med Parasitol 4: 50-53.

[15] Plekhova N. G., Somova L. M., Okhotina S. V., Drobot E. I., Goncharuk Yu. N. (2006) Metabolic activity of neutrophils in pseudotuberculous infection. J Microbiol Epidemiol Immunobiol 3: 43-47.

[16] Navarini A. A., Lang K. S., Verschoor A., Recher M., Zinkernagel A. S. et al. (2009) Innate immune-induced depletion of bone marrow neutrophils aggravates systemic bacterial infections. PNAS 106 (17): 7107-7112.

[17] Loyda Z., Gossrau R., Shibler T. (1982) Histochemistry of enzymes: laboratory methods. Moscow: The World.

[18] Schulz K., Kerber S., Kelm M. (1999) Reevalution of the Griess method for determining $\mathrm{NO} / \mathrm{NO}_{2}-$ in aqueous and protein-containing samples. Nitric Oxide 3 (3): 225-234.

[19] Totolyan A. A., Freidlin I. S. (2000). Cells of the immune system. Saint-Petersburg: Science. 2000.

[20] Kohlman J., Rem K. G. (2000) Visual Biochemistry. Moscow: The World. 
[21] Evans T. J., Buttery L. D. K., Carpenter A., Springall D. R., Polak J. M., Cohen J. (1996) Cytokine-treated human neutrophils contain inducible nitric oxide synthase that produces nitration of ingested bacteria. Cell Biol 93: 95539558.
[22] Fang F. C., Vazquez-Torres A. (2002) Nitric oxide production by human macrophages: there's NO doubt about it. Amer J Physiol 282 (5): 941-943. 